\title{
LA TAREA DE SER JOVEN EN UNA LOCALIDAD PERIFÉRICA.
}

\author{
THE DUTY OF BEING YOUNG IN A SUBURBAN AREA ${ }^{1}$
}

Páginas $53-62$

\section{Alejandro J. Capriati ${ }^{2}$ \\ Instituto de Investigaciones Gino Germani (FSOC /UBA)}

Palabras clave: juventud, música, noche, violencia, Argentina.

Keywords: youth, music, night, violence, Argentina.

\section{Resumen}

El artículo analiza las experiencias musicales y las actividades nocturnas en un área suburbana de Buenos Aires, Argentina. ¿La música despierta el descontento generacional y es una fuente para la protesta y la movilización política? ¿Las letras de las canciones contribuyen a resolver problemas sociales y la violencia? ¿La música reproduce estereotipos de género machistas y heteronormativos heredados y genera más violencia? Basado en una investigación cualitativa, que articula observación participante y entrevistas semiestructuradas, describo las experiencias musicales y las escenas nocturnas de tres grupos de jóvenes. En particular, analizo cómo los aparentemente contradictorios estilos musicales (rock, reggae, tropical-latino) coexisten en la misma escena y en los mismos individuos. La música que escuchan y producen, como los espacios musicales en los cuales se encuentran, configura un modo de ser joven, varón y mujer, y hace visible formas en que la violencia juega en sus vidas.

\section{Abstract}

This paper shows the analysis of the young's music experiences and night activities in a suburban area of Buenos Aires, Argentina. It is based on questions such as "Can music spur unrest and provoke political protests and demonstrations? Can lyrics contribute to solve social and violence problems? Does music reproduce inherited heteronormative and gender stereotypes and cause more violence?" This project is based on a qualitative research which includes participant observation and semi-structured interviews to describe
* Este artículo forma parte de una investigación doctoral sobre actividades cotidianas, recreativas y musicales en varones y mujeres jóvenes en el área metropolitana de Buenos Aires bajo la dirección de Ana Lía Kornblit. Agradezco a las bandas, músicos y asistentes con quienes compartí el trabajo de campo entre 2007 y 2009.

1 Traducción de Carlos A. Muñoz T. Revisión Centro de Traducción del Instituto de Idiomas UAM.

2 Doctorado en Ciencias Sociales en la Facultad de Ciencias Sociales, Universidad de Buenos Aires (FSOC/UBA). Docente de la materia Psicología Social de la carrera de Sociología (FSOC/ UBA). Becario del Consejo Nacional de Investigaciones Científicas y Técnicas (CONICET) con sede en el Instituto de Investigaciones Gino Germani (FSOC/UBA).Correo electrónico: acapriati@conicet.gov.ar alejandrocapriati@yahoo.com.ar

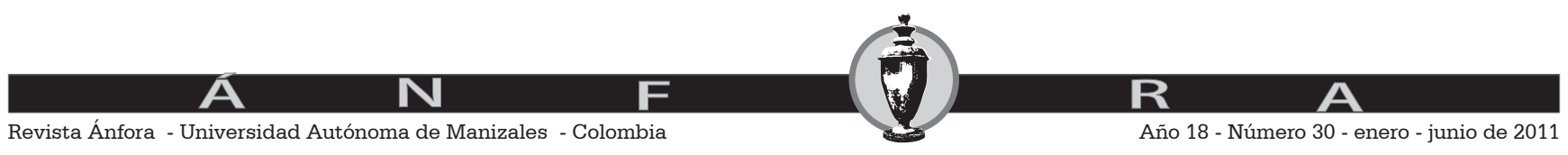


music experiences and night scenes of three music groups of young people. Particularly, this paper analyzes how apparently contradictory music styles (rock, reggae, and latin tropical music) coexist in the same night scenes and individuals. The music they listen to and produce and the scenes they meet in framing their way of being a young man or woman and makes visible what about evidences the roles that violence plays in their lives.

\section{-I. Introducción. -II. Herramientas teórico-metodológicas. -III. Noches de barrio. -IV. Narrativas compartidas. -V. Conclusiones.}

\section{Introducción}

En este artículo analizo modalidades de ser varón y mujer joven en su relación con la música y la noche, a partir de una investigación empírica con tres grupos de personas de una localidad suburbana o periférica de Argentina.

¿La música despierta el descontento generacional y es una fuente para la protesta y la movilización política? ¿Las letras de las canciones contribuyen a resolver los problemas sociales y la violencia? ¿La música reproduce los estereotipos de género machistas y heteronormativos heredados y genera más violencia? Estos interrogantes identifican temas relevantes que relacionan juventud, cultura, política y género.

El eje del artículo se sitúa en la intersección de dos campos de la investigación social: los estudios sobre juventudes y cultura, por un lado, y los estudios de promoción de la salud, género y derechos, por otro. La problemática teórica, adaptada de Ana María Ochoa Gautier (2006), se interroga por los modos en que los sujetos jóvenes usan la música para construir modos de conocer y de estar en el mundo en contextos de violencia. A partir de un enfoque socioantropológico se utilizó observación participante y entrevistas. También se construyó un corpus de análisis a partir de la producción musical de los grupos de la localidad.

En América Latina, las investigaciones sobre juventud y cultura emergieron en los años ochenta y se multiplicaron durante los noventa (Vila, 1985; Hermano Vianna, 1987; Alabarces y Varela, 1988; Reguillo Cruz, 1991; Margulis y otros, 1994, entre otros). Éstas dialogaron con estudios previos, por ejemplo, sobre subculturas, en Inglaterra desde los sesenta (Jefferson, Hebdige, Clarke, [1975] 2005) y anteriormente, los de la Escuela de Chicago sobre urbanismo y grupos juveniles que habían generado una ruptura metodológica y conceptual (Park, 1952, Trasher, 1963, entre otros). A partir de las técnicas de observación etnográfica, se aproximaron a la juventud de un modo diferente a la posición psicológica dominante, inspirada en la obra de Stanley Hall, sobre la adolescencia como una etapa de crisis y moratoria social.

De acuerdo a la CEPAL, América Latina atraviesa un momento con auspicios y dramas: si bien existe crecimiento en el desarrollo de capacidades, las

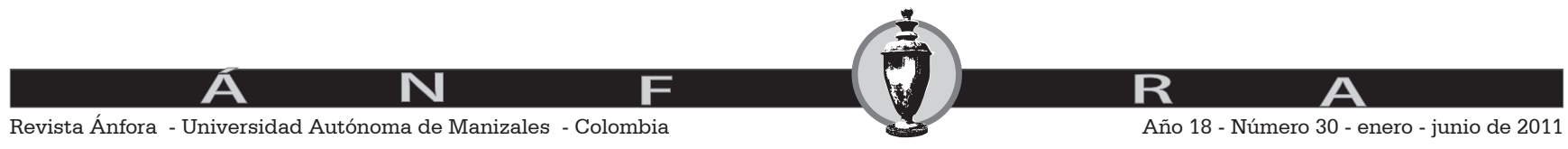


oportunidades continúan segmentadas por niveles de ingresos, distribución geográfica, racial y de género (2008). La región suele ser definida como una de las más desiguales y violentas del planeta. No es tan fácil explicar cómo se relacionan estos dos fenómenos. Las explicaciones ensayan al menos tres respuestas: la desigualdad como generadora de violencia; la violencia como exacerbación de la desigualdad; y el tercer camino que las muestra a ambas atrapadas en un círculo vicioso (Francisco Gutiérrez, 2009). En este escenario, la música es celebrada por algunos autores debido a su presunta capacidad de dar respuesta a la violencia, y es condenada por otros por la incitación a la misma (Ochoa Gautier, 2006). Ambos postulados, explica Ochoa Gautier, asumen una relación causal entre textualidad, práctica musical y efecto social que es necesario desarmar para evitar pensar la música o la violencia como factores externos que hay que estimular o erradicar para reconstruir lo social.

Uno de los desafíos contemporáneos en América Latina radica en captar la multiplicidad en los modos de ser joven en escenarios diversos y desiguales (Reguillo Cruz, 2000: 30). El espacio de la noche y la experiencia de la música son alternativas privilegiadas para captar los contornos de estas modalidades.

Es probable encontrar varones jóvenes que están armando grupos de música rock, reggae, hip hop, música tropical o algo que ni ellos están interesados en clasificar en casi todos los rincones de un barrio periférico o suburbano. En Argentina, como en otros países, la música es una práctica significativa en la vida de las personas, los y las jóvenes. Una investigación realizada en escuelas medias de Argentina (Kornblit, 2006) señala que casi la totalidad de los varones y las mujeres jóvenes escuchan música sin diferencias de sexo, edad o estrato socioeconómico. Más de la mitad de la muestra escucha tres o más horas de música diariamente (55,7\% durante la semana y $63,3 \%$ durante el fin de semana). Mirar televisión, hacer deportes, jugar con la computadora, realizar actividades artísticas o leer, son actividades a las cuales les dedican una menor cantidad de horas en sus actividades diarias.

La única opción que supera a la música, entre las actividades que le dedican semanalmente cinco horas o más, es salir con amigos (música: $29,1 \%$ durante la semana y $34,4 \%$ durante el fin de semana; salidas con amigos: $29,6 \%$ y $52,3 \%$, respectivamente). Casi un tercio de la muestra sale todos los fines de semana con una frecuencia de dos o tres noches. Y casi la totalidad de la muestra $(83,3 \%)$ sale con el mismo grupo de amigos.

En el apartado siguiente se definen las herramientas teórico-metodológicas. Luego se describe la escena nocturna y las experiencias musicales.

\section{Herramientas teórico-metodológicas}

La estrategia metodológica, inscripta en una perspectiva socio-antropológica, es cualitativa y tiene un carácter descriptivo. Realicé observación participan-

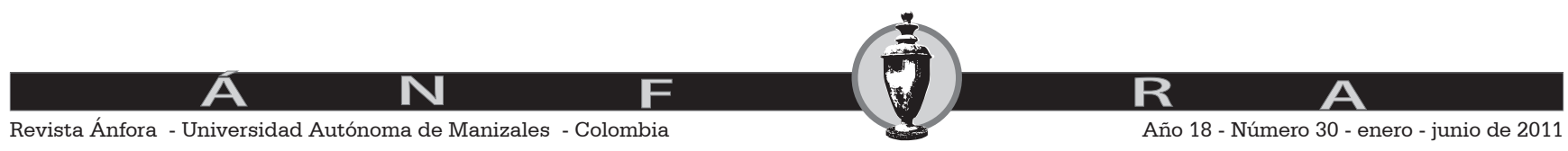


te durante los ensayos y festivales de música rock en una localidad del Gran Buenos Aires. La música rock no es el objeto de estudio de la investigación sino la puerta de entrada al trabajo de campo. La muestra siguió el criterio de muestreo teórico o por propósitos (Maxwell, 1996) y el material empírico se procesó de acuerdo a los lineamientos de la teoría fundamentada (Glaser y Strauss, 1967). Realicé treinta entrevistas semi-estructuradas (varones y mujeres, músicos y asistentes), asistí a catorce festivales, a más de veinte ensayos y analicé un corpus elaborado a partir de la producción musical de tres grupos de música.

Para pensar la cuestión juvenil parto del concepto de condición juvenil. La condición juvenil es una categoría relacional (adquiere sentido en función de lo no juvenil), históricamente construida, situacional, cambiante y transitoria (Pérez Islas, 2000). La condición juvenil se articula social y culturalmente con la edad, con la generación a la que se pertenece, con la clase social de origen, con el género y con la ubicación en la familia. (Margulis y Urresti, 1996:29). Las mujeres y los varones jóvenes son pensados como sujetos de discurso y sujetos con capacidad y competencias para apropiarse de objetos y recursos, materiales y simbólicos (Reguillo Cruz, 2000:36). La apuesta teórica, como afirma Chaves, es pensar la juventud como relación y como posibilidad. (2005: 26).

El análisis de la música no se centra en el texto musical, sino en los usos que los y las jóvenes hacen de la música. La música es una experiencia emocional intensa que usan para pensarse a sí mismos y una forma de expresar públicamente lo privado. (Frith, 2003). La práctica musical da forma a las experiencias afectivas y reflexivas de los sujetos y construye significados singulares y colectivos (Maheirie, 2002). El término escena nocturna, adaptación del término original escena musical (Straw, 1991; Bennet, 2004; y otros) permite analizar cómo los individuos se mueven entre escenas.

Respecto al trabajo de campo, se contactó a tres grupos de varones y mujeres que no se conocían entre sí. El trabajo de campo estuvo marcado por las dificultades para entrar y salir de la localidad. Era frecuente que los contactos se preocuparan por mi seguridad y aguardaran conmigo el inicio del servicio del transporte público luego de los recitales nocturnos. Con la música recorrí el barrio y asistí a recitales de música (rock, pesada, reggae o ska, etcétera) que no tenían más publicidad que unos afiches y avisos por mensaje de texto entre los conocidos. El trabajo de campo me sorprendió y desorientó. Me sorprendí cuando los entrevistados no esperaban nada a cambio y me desorienté al observar la heterogeneidad y diversidad musical que convive en una misma zona de un barrio periférico. Pertenezco a un segmento que ha tenido el privilegio de estudiar en la universidad y encontar un oficio a través de las becas de formación doctoral del sistema científico. Investigo con el compromiso de contribuir a la generación de políticas públicas con la juventud para consolidar, en fin, una sociedad más democrática y equitativa.

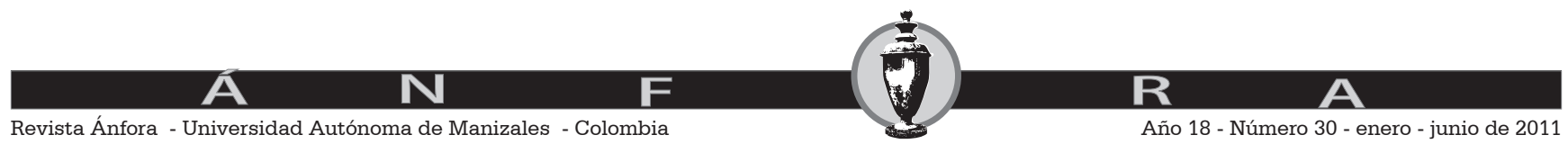




\section{Noches de barrio}

Las muchachas y muchachos que contacté y entrevisté eligen como opción recreativa los fines de semana asistir a recitales o festivales de bandas de rock. Quienes circulan por estos espacios nocturnos son de la misma localidad o del barrio vecino. En su mayoría nacieron y se criaron en esta zona, a diferencia de sus abuelos y padres ${ }^{3}$. Tienen entre dieciséis y veintiocho años de edad: los más jóvenes cursan el secundario y entre los mayores son pocos los que no pudieron terminar la instrucción primaria. Algunos tienen empleo "en blanco" (están inscriptos legalmente); mientras que el resto trabaja "en negro" o consigue cada tanto alguna actividad informal. Algunos participaron cuando eran más jóvenes en grupos religiosos católicos y otros en movimientos sociales, como el Movimiento de Trabajadores Desocupados (MTD).

Por lo general, los varones y mujeres jóvenes que asisten regularmente a los recitales y festivales no van a bailar a una rave, a un boliche o una bailanta. La casa de un amigo, una esquina del barrio, el centro cultural o el bar son posibles escenarios para tocar o ver un grupo de música en su propio barrio. La localidad alterna zonas urbanizadas con asentamientos precarios y villas. Como tantas otras zonas, carga con fama de barrio peligroso. Las noticias de los diarios y la televisión describen episodios de robos, violencia e inseguridad. Para ellos, sin embargo, el barrio es tan peligroso y violento como cualquier otro. En las conversaciones se filtran historias en las cuales un amigo o ellos mismos padecieron detenciones arbitrarias y situaciones de abuso policial.

Todos tienen en común la práctica de asistir a recitales y festivales de bandas de rock. Lo significativo no es tanto el término banda de rock, lo cual puede prestar a confusión. El imaginario en torno al rock y al rockero, sea en su versión romántica como rebelde o en su versión degradada como reventado por el consumo de drogas, nubla la producción de una sociología de la juventud en varios sentidos. El término banda de rock no define tanto un estilo particular, ya que por debajo de dicha etiqueta se desplazan propuestas musicales que apelan a diferentes sonoridades, sino un modo de vincularse con la música. Tocar un instrumento, cantar, escribir una letra, armar una canción son actividades que se llevan a cabo de modo grupal. No son solistas ni estudian música en el conservatorio ${ }^{4}$. Se reconocen como una banda en tanto tocan en vivo. Ensayar sin tocar los fines de semana con público no es suficiente. Ser parte de una banda de rock significa tener una experiencia musical grupal y tocar en vivo. ${ }^{5}$

Ser parte de grupo de música no deja ingresos económicos; por el contrario, se ahorra dinero para afrontar los gastos. Vivir de la música es un sueño lejano para algunos y para otros está, directamente, excluido de sus expectativas o intereses. Para algunos, la música tiene que generar una nueva conciencia política. Algunos de ellos dan clases de guitarra en un comedor en una villa cercana. Entre algunos de los músicos y asistentes formaron un centro cultu-
3 Saben por sus padres que hasta no hace más de cuarenta años éste lugar era un gran descampado La instalación de fábricas y frigoríficos hacia mediados del siglo veinte (y su posterior cierre décadas más tarde), la afluencia de migrantes del interior del país e inmigrantes de Paraguay y Bolivia transformaron la fisonomía de esta localidad.

4 Esta última afirmación debe ser atenuada. Algunas sí han comenzado sus estudios de música pero no invalida la proposición acerca de la música como experiencia grupal.

5 Estos grupos de música se forman entre amigos del barrio y compañeros del colegio secundario. Son personas jóvenes, desde los dieciséis hasta los veintiocho años de edad, y por lo general, aprendieron a tocar sin profesor ni escuela de música.

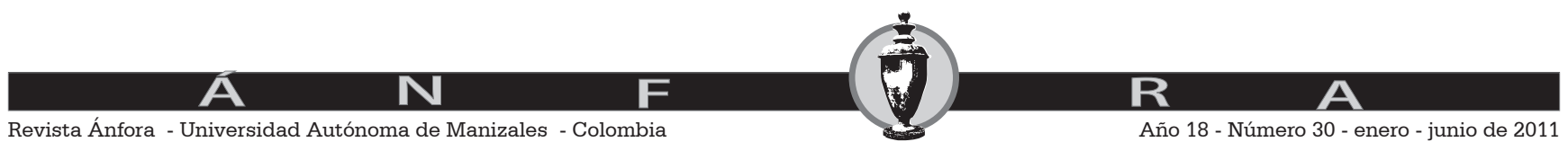


ral y organizan festivales solidarios de música para apoyar diferentes causas. Para todos, la música debe generar un espacio de diversión. Las bandas se construyen sobre una base de participación horizontal, y en algunas se realizan asambleas para tomar las decisiones.

La participación en un grupo musical permite también ser protagonista de la escena nocturna. A través de la participación en una banda obtienen el reconocimiento de otros. No es necesario tener éxito comercial. "El sueño ya está cumplido" señalan varios integrantes sobre las ganancias y las pérdidas de pertenecer. Ser protagonista de la escena nocturna asegura, o por lo menos brinda más oportunidades de divertirse, encontrarse con amigos, conocer parejas o compañeras para encuentros afectivo-sexuales. Esta escena es un espacio de sociabilidad heterosexual. En esta escena no circulan personas con sexualidades no heterosexuales. La pregunta sobre la presencia de gays y lesbianas genera desconcierto. Las expresiones que se utilizan en los chistes y los insultos remiten a una cultura machista y homofóbica. La mayoría de las bandas están integradas por varones y no hay grupos formados exclusivamente por mujeres.

Los eventos que forman esta escena se organizan en dos modos típicos. En algunas oportunidades, un grupo organiza la fecha: invita a otros grupos, consigue lugar, equipo de sonido y bebida y publicita la fecha. Para estas actividades se cuenta con la colaboración de padres, madres, hermanos y amigos. Durante el evento, participan todos: algunos muestran sus dibujos o sacan fotos, otros diseñan el escenario o manejan la barra de bebidas. En otras oportunidades, un grupo se suma a una fecha organizada por un bar. Para poder tocar tienen que comprar entradas (30, 50, 100, depende el local). Para los grupos en formación o de baja convocatoria es difícil vender las entradas que, por lo general, terminan regalando.

Esta escena, organizada de uno u otro modo, presenta similitudes y diferencias con otras actividades. Estar en la noche es la dimensión que comparten las actividades recreativas juveniles. Como afirma Blázquez (2008), la noche es la práctica a través de la cual niños y viejos se hacen jóvenes. En esta localidad de Buenos Aires estos eventos musicales no son la opción más elegida entre el segmento joven. En el barrio domina la música tropical, en sus diversas expresiones. Mientras en los recitales y festivales los números de los asistentes se mueven por decenas y centenas, en las bailantas asisten miles y miles de personas para divertirse. Las diferencias entre las opciones no se refieren sólo al número de asistentes. De acuerdo a los entrevistados, los recitales y festivales son espacios menos violentos que las bailantas/boliches en tanto se generan menos peleas entre los asistentes.

En los recitales y festivales, los problemas y diferencias, por el motivo que fueran, intentan ser resueltas de un modo no violento. Pertenecer a barrios distintos y tener propuestas musicales diversas no son motivo suficiente para pelearse. La caracterización musical de la escena nocturna no es sencilla y los gustos de las personas no pueden encasillarse. En estos eventos tocan

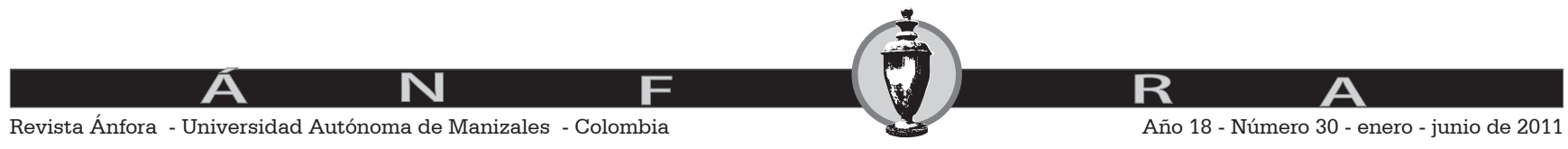


grupos de barrios vecinos que no se conocen ni tienen el mismo estilo musical. Para estos grupos, es indispensable compartir la noche con otros grupos, sea para afrontar los gastos o para asegurar un mínimo de convocatoria. Las propuestas musicales (desde sonoridades más melódicas hasta otras más pesadas y alternativas) conviven en una misma noche. Las personas que transitan estas escenas nocturnas tienen gustos diversos. Incluso el gusto de cada persona es diverso. Entre los músicos y asistentes ninguno se identifica como rockero. En otras palabras, en la misma escena conviven personas que escuchan música rock $^{6}$, música reggae ${ }^{7}$ y música tropical ${ }^{8}$. Sin embargo, la violencia está presente en esta escena nocturna. Algunas de las formas que asume la violencia se desarrollan en el apartado siguiente.

\section{Narrativas compartidas}

Cada recital o festival es un acontecimiento esperado. Tocar en vivo es el momento más festivo para una banda y su público. Así como la escritura exige la lectura, la música reclama la escucha. Participar en una banda de rock les permite hacer música. En ese hacer música las letras son un material significativo que delinea cierto contorno simbólico de la escena. La producción musical no es homogénea ni todos los grupos elaboran letras para sus músicas. Entre aquellos grupos que le dedican atención a las letras es posible identificar referencias y estilos narrativos que tienen cierto "parecido de familia".

En las canciones se relatan historias de desamor, soledad, frustración y alegría, como así también cuestiones como la discriminación y la represión. Más que un manifiesto, el relato asume la forma de un testimonio personal que brinda aliento para no dejarse atrapar por los fracasos cotidianos y la desilusión. El testimonio, en primera persona, es una valoración de la palabra y la persuasión. A diferencia de otras narrativas musicales, no hay una valoración del ejercicio de la violencia física.

Si bien los textos de canciones no necesaria ni principalmente describen prácticas de quienes los escuchan, la música es una referencia simbólica importante para esos sujetos. Las canciones no son mandamientos que las personas, por más jóvenes o pobres, adhieren sin ningún tipo de mediación. Es un salto analítico asociar letras con comportamientos. Existen mediaciones simbólicas que deben ser sopesadas en el análisis social como conocer la escena recreativa y la vida cotidiana de las personas. Esto no significa afirmar que el análisis de los textos musicales sea irrelevante. Los textos son referencias con las cuales las personas dialogan. Al igual que en otras experiencias estéticas, los textos musicales no clausuran su sentido; la persona que escucha completa el sentido en su horizonte bio-biográfico.

El tema de la policía y el gatillo fácil atraviesa, tanto las producciones de estos grupos como las producciones de los grupos ya masivos que escuchan . La expresión gatillo fácil comenzó a circular en Argentina hacia fines de los años ochenta para describir casos de violencia y abuso policial con uso de armas de fuego. Basta tipear "gatillo fácil" en Youtebe para escuchar la mis-
6 Los grupos de rock mencionados no siempre son los mismos y remiten a artistas de la escena local y de otros países. Las bandas que se escuchan constituye un listado inmenso. Algunos de estos jóvenes accedieron, a través de sus hermanos mayores, a Frank Zappa, Led Zeppelin, The Cream o Pink Floyd, entre otros nombres célebres del rock inglés de los años sesenta y setenta. Para la mayoría, grupos del rock argentino como Patricio Rey y sus Redonditos de Ricota o La Renga son una referencia ineludible. (Para estos dos grupos de rock local la independencia como productores es una marca de distinción que se expresa, entre otras cuestiones, en la no firma con empresas de la industria discográfica y la no participación en festivales con patrocinio gubernamental o empresarial). Otros también escuchan música country y folk rock, influenciados por los gustos de sus padres. Varios de estos últimos escuchan también cumbia norteña, santafesina y villera. El abanico de las preferencias incluye, aunque de modo marginal, el tango, músicas folclóricas del interior de país y músicas de países limítrofes.

7 Los entrevistados corroboran la creciente difusión y apropiación de la música reggae en el barrio. La música reggae en Argentina emergió en los años ochenta con propuestas musicales tan diversas como Todos Tus Muertos, Los Pericos o Sumo y diferentes posiciones en relación con la cultura rastafari, su cosmovisión religiosa, su mirada política y la relación con la industria discográfica. Resistencia Suburbana, Dread Mar I, Nonpalidece, Los Cafres, Fidel Nadal, son algunos ejemplos entre decenas de grupos que tocan regularmente.

8 No es posible enumerar aquí todos los grupos de cumbia. Cabe destacar que se escucha cumbia

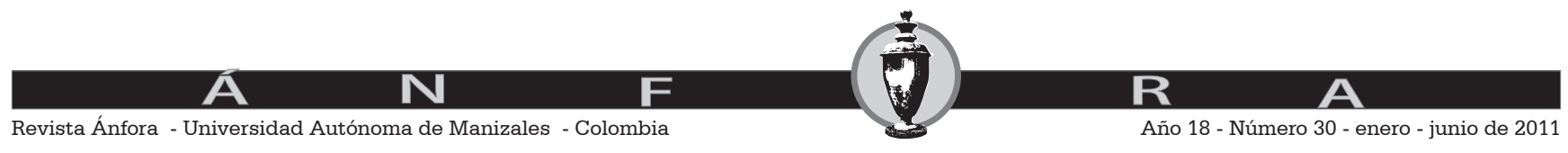


ma temática con música diferente, sea cumbia villera (grupo: Flor de Piedra, letra: Pablo Lescano), punk rock (Dos Minutos) o heavy metal (Malón). Estos textos musicales definen el término ("permiso para matar" / "enfrentamientos que no existen, defensa propia que no convence"), explican cómo funciona ("esto le pasa a cualquiera" / "Un gatillo fácil siempre se puede encontrar en una esquina, en cualquier lugar"), dan ejemplos ("No se olviden de Cabezas, de Bulacio, Bru y Bordon Ay la lista es tan larga que no puedo cantar hoy" / "Pasó en Budge, en Wilde también") y consejos ("Cuidate"/ "Dios no quiera que en la lista el siguiente sea vos" / "Por eso acordate cuando vas a salir, que en está selva no se puede dormir" / "Cuídate si andás por la calle, la yuta te puede cazar"). Como una de las mejores cosas que se puede hacer con la música es escucharla, los invito a tipear esas palabras. En este caso, quienes escuchan cumbia, punk rock o cumbia reciben el mismo consejo. Tienen en común un mismo problema: se seguridad personal cuando transitan la noche. La música, a fin de cuentas, es un interlocutor legítimo porque da cuenta de las cosas que les suceden a las personas.

\section{A modo de cierre}

La investigación aporta líneas de interpretación para profundizar el análisis acerca de los modos en que las personas usan la música para conocer y estar en contextos de violencia.

El uso de la música es diverso. La música es una experiencia no sólo de expresión sino también de conocimiento. El primer dato a tener en cuenta es que los y las jóvenes no escuchan un único estilo musical y se resisten a ser definidas por éste. Los gustos musicales de los varones y mujeres jóvenes que circulan por estos eventos permiten dibujar una rockola imaginaria en la cual coexisten estéticas diversas. El segundo dato relevante es que las personas jóvenes arman sus propios grupos musicales y/o participan en la organización de recitales. La participación en un grupo musical asume la forma de una banda de rock, pero las propuestas musicales apelan a sonoridades diversas. Para los músicos como para los asistentes, la música es una experiencia constructora de la cotidianidad y sus espacios nocturnos. En suma, las canciones permiten conocer acerca de las preocupaciones de los sujetos jóvenes.

En este artículo no encontramos respuestas definitivas, pero sí algunas pinceladas que permiten explorar la complejidad de la condición juvenil en su relación con la música y el espacio de la noche. norteña, santafesina o cumbia villera y que Pablo Lescano es una de las figuras destacadas. Por lo general, son las mujeres jóvenes que transitan por esta escena quienes manifiestan que escuchan de todo menos cumbia. El rechazo a la música tropical, especialmente a la cumbia villera, se debe al discurso sexista y machista de algunas de sus producciones más exitosas. Para profundizar sobre música tropical y cumbia villera ver Cragnolini, 2004.

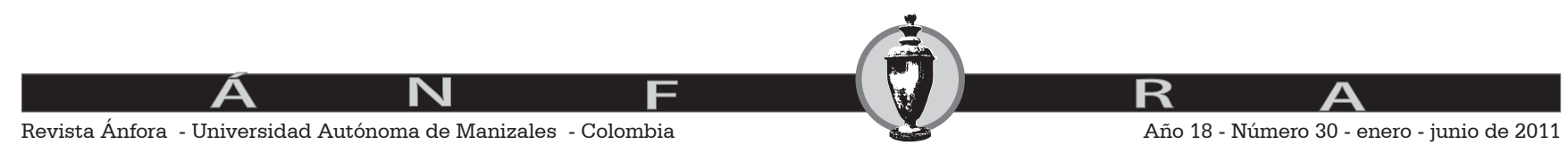




\section{Referencias bibliográficas}

Alabarces, P. (1993) Entre gatos y violadores. Buenos Aires: Ediciones Colihue.

Alabarces, P. y Varela, M. (1988) Revolución, mi amor. El rock nacional [19651976]. Buenos Aires: Editorial Biblos.

Blázquez, G. (2008) "Nosotros, Vosotros y Ellos. Las poéticas de las Masculinidades Heterosexuales entre jóvenes cordobeses". En Revista Transcultural de Música, \#12 ISSN:1697-0101. Recuperado el 04-05-2010 http://www.sibetrans.com/trans/trans12/art06.htm

Bourdieu, P. (1988) La distinción. Criterio y bases sociales del gusto. Madrid: Taurus.

CEPAL (Comisión Económica para América Latina y el Caribe) (2008) Juventud y cohesión social en Iberoamérica. Un modelo para amar. Santiago de Chile: Naciones Unidas.

Chaves, M. (2005) "Juventud negada y negativizada: representaciones y formaciones discursivas vigentes en la Argentina contemporánea". Revista Última Década Año 13 No 23 Viña del Mar: CIDPA. Pp. 9-32. Versión electrónica http://www.cidpa.cl

CRAGNOLINI, A. (2004). "Violencia social, adolescencia, significante sonoro y subjetividad: el caso de la cumbia villera en Buenos Aires". Ampliación crítica de la ponencia "Soportando la violencia. Modos de resignificar la exclusión a través de la producción y consumo musicales". Ponencia presentada ante el $V$ Congreso de la IASPM- $A L$, Río de Janeiro.

Feixa, C. (2006) "Generación XX. Teorías sobre la juventud en la era contemporánea", Revista Latinoamericana de Ciencias Sociales, Niñez y Juventud. Vol. 4, No. 2, Recuperado el 25-06-2009 de http://www.umanizales. edu.co/revistacinde/Vol4/Carles\%20Feixa.pdf

FRITH, S. (1996). "Música e identidad". En: Hall, A.; du Gay. Cuestiones de identidad cultural. Buenos Aires, Argentina - Madrid, España: Amorrortu editores.

(1987). "Towards an aesthetic of popular music". En: Richard Leepert y Susan McClary (eds) The politics of composition, performance and reception. Cambridge: Cambridge University Press.

Glaser, B., Strauss, A. (1967) The discovery of grounded theory. Nueva York - Aldine Publishing Company,

Gutiérrez Sanín, F. (2009) "Violence and social inequalities". En FORUM, Latin American Studies Association, Pittsburgh, LASA.

Hall, S. y Jefferson, T. (2000) [1975]. Resistance through rituals. Youth subcultures in post-war Britain. London-New York: Routledge.

Kornblit, A. L. (2007) Juventud y vida cotidiana. Buenos Aires: Bliblos,.

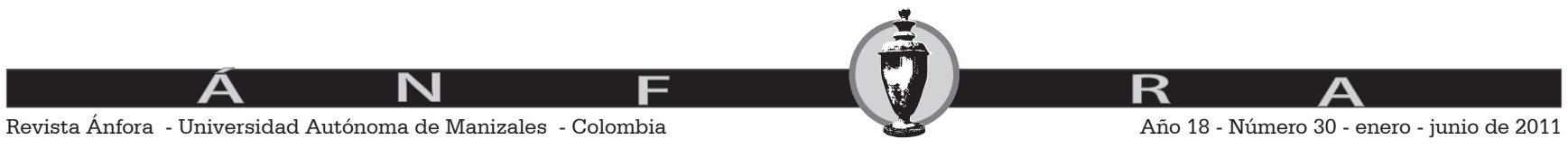


Kornblit, A. L y otros (2006) Salud y enfermedad desde la perspectiva de los jóvenes. Un estudio en jóvenes escolarizados en el nivel medio de todo el país. Documento de Trabajo $N^{\circ}$ 47. Instituto de Investigaciones Gino Germani, Buenos Aires.

Maheirie, K. (2002) "Música popular, Estilo estético e identidad cocletiva", En Revista Psicología Política, Sociedade Brasileira de Psicologia Política, Vol.2, São Paulo: SBBP.

Margulis, M. y Urresti, M. (1996). La juventud es más que una palabra. Ensayos sobre cultura y juventud. Buenos Aires, Biblos.

Margulis, M. (1994). La cultura de la noche. Buenos Aires, España: Espasa Calpe.

Maxwell, J.A. (1996) Qualitative research design. An interactive approoach. Sage Publications.

Ochoa Gautier, A. M. (2006) "A Manera de Introducción: La materialidad de lo musical y su relación con la violencia", En Revista Transcultural de Música, Vol. 10, Recuperado el 01-03-2009 de http://www.sibetrans.com/ trans/trans10/ochoa.htm

Pérez Islas, A. (2000) Jóvenes e instituciones en México. 1994-2000. México: SEP-Instituto Mexicano de la Juventud.

Pujol, S. (2005) Rock y dictadura. Buenos Aires: Emecé Editores.

Reguillo Cruz, R. (2000) Emergencia de culturas juveniles. Estrategias del Desencanto. Buenos Aires: Grupo Editorial Norma.

(1991). En la calle otra vez. Las bandas: identidad urbana y usos de la comunicación. Guadalajara, México: Iteso.

Rincon, O. (2009) "Narco.estética y narco.cultura en Narco.Colombia". Revista Nueva Sociedad, Julio- Agosto.

Vianna, H. (1987). O mundo funk carioca. Rio de Janeiro, Brasil: Jorge Zahar Editor.

Vila, P. (1995) "Identidad narrativas y música. Una primera propuesta para entender sus relaciones", En Sibetrans. Revista Transcultural de Música, $\mathrm{N}^{\circ}$ 2, Recuperado el 1 de marzo de 2006 en http://www.sibetrans.com/trans/ trans2/vila.htm

(1985) "Rock nacional: crónicas de la resistencia juvenil", En Jelín, E. (comp.) Los nuevos movimientos sociales/1, Buenos Aires, CEAL.

Vila, P., Semán, P. (1999) "Rock chabón e identidad juvenil en la Argentina neoliberal", En Filmus, D. (comp.) Los noventa: política, sociedad y cultura en América Latina y Argentina de fin de siglo. Buenos Aires: Flacso Eudeba.

Straw, W. (1991) "Systems of Articulation, Logics of change: communities and Scenes in Popular Music". Cultural Studies, vol. 3, pp- 368-88.

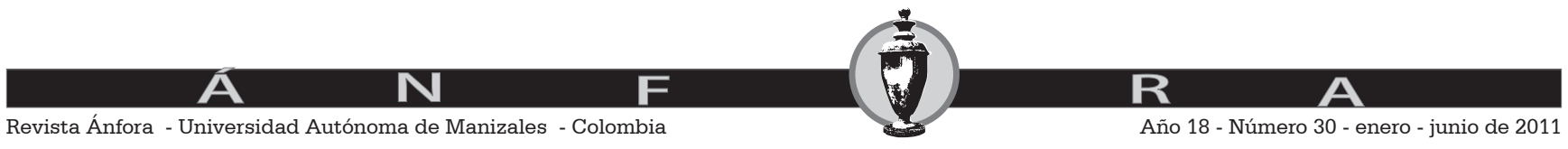

